\title{
Head Transplantation: The Ultimate Level that Medicine has not yet Achieved
}

\author{
Habib SARIKAYA, Omur SAYLIGIL \\ Eskisehir Osmangazi University, Faculty of Medicine, Department of History of Medicine and Ethics, Eskisehir, Turkey \\ Corresponding author: Habib SARIKAYA habibsarikaya45@gmail.com
}

\section{ABSTRACT}

The process of head transplantation is reviewed according to Cartesian philosophy. Recent developments in head transplantation were followed with great interest in the media and society. The surgeon Sergio Canavero stated that he could perform head transplantation. His ethical approaches to the procedure are evaluated, and the methodological suitability of the procedure with regard to the scientific ethics is discussed. The perception of the head transplantation process in the media and society is described as a phenomenon, and the relationship between society and science is evaluated. Ethical duties and responsibilities are highlighted as an area of knowledge. According to the perspective of Cartesian philosophy, it is not yet possible to perform head transplantation under the conditions of today's medicine.

KEYWORDS: Head transplantation, Cartesian philosophy, Ethics

\section{Head Transplantation: A Sensational News Story for the Media}

$\mathrm{I}$ n mid-September of 2015, an Italian surgeon's claim to be able to conduct head transplantation received wide coverage on the international and Turkish media. In the news, the surgeon, Sergio Canavero, announced that he would be prepared to graft a living person's (recipient's) head onto a brain-dead person's (donor's) body in 2 years' time. Canavero explained the technical aspects of surgery approximately as follows: To allow cells to remain alive without oxygen for a considerable period of time, the first step would be to lower the temperatures of the donor's body and the recipient's head. The heads of the donor and the recipient would be cut off at the same time. Tissues around the neck would be cut first. Main veins would be connected to each other with the help of small tubes, and then the spinal cords of both donor and recipient would be cut. Subsequently, the body of the braindead person, in whom mobility was still possible, would be connected to the head of the living person, whose neurological function was damaged. To do this, polyethylene glycol would be used to connect the terminals of donor's and recipient's spinal cords. The next stage would be to reattach and stitch together muscles and vessels $(7,9,11)$.

This news sparked a broad discussion and criticism regarding the technical and ethical aspects of the procedure in the field of medicine. Canavero argued that efforts related to human head transplantation have a long history. It was announced for the first time at the meeting of the Turin Advanced Neuromodulation Group in 2013 that challenges to head transplantation were solved. Canavero claimed that he would overcome the obstacles through spinal cord anastomosis in accordance with the GEMINI protocol. In the article published in July 2013 in Surgical Neurology International, Canavero explained the details of the GEMINI procedure, arguing that his "paper lays out the groundwork for the first successful human head transplant" $(1,2)$. Furthermore, Xiaoping Ren, a Chinese surgeon, stated that he had conducted over 1000 head transplantations with mice since 2013 (6). He reported that the operation took approximately 10 hours, and that recipient mice lived, on average, 1 day. After these explanations, Canavero and Ren decided to collaborate on head transplantation. The volunteer they sought came from Russia. Valery Spiridonov, 
a Russian computer engineer born in 1985 with WerdnigHoffmann disease, a congenital disease leading to muscle wasting, was predicted to have a poor life expectancy. Mr. Spiridonov decided to undergo head transplantation, which was likely to shorten life expectancy further.

Canavero and Ren announced at a conference in Northeastern China that they would provide Spiridonov with a new body. Receiving a grant of approximately $\$ 2$ million from Chinese academic and governmental funds, Canavero mentioned that the surgery team best qualified to perform head transplantation was probably in China (7). During the meeting of the Turin Modulation Group in November 2017, Canavero stated that he had performed a head transplantation successfully on cadavers. Canavero stated that the surgery, which lasted 18 hours, would be implemented on a living person soon. In the same meeting, however, it was stated that Mr. Spiridonov had decided against volunteering for the head transplantation (12).

After these incredibly rapid developments, the scientific world started to voice criticism against head transplantation. Arthur Caplan, of the New York University School of Medicine, stated that "It's science through public relations. When it gets published in a peer-reviewed journal I'll be interested. I think the rest of it is nonsense." Criticizing Canavero for "flying to the next galaxy when it would be nice to set up a colony on Mars,"Caplan invited Canavero to use the GEMINI technique on people with spinal cord injuries rather than attempting head transplantation. Thomas Cochrane, of the Center for Bioethics at Harvard Medical School, stated that the idea of head transplantation generated excitement before it was warranted and added, "As far as I can tell, that operation has mostly been about publicity rather than the production of good science" (7). Jerry Silver, neurology professor at Case Western Reserve University School of Medicine, noted that "Each muscle, bone, and everything will be cut. After all these cuts, can you imagine what kind of pain the patient will suffer in his head when he wakes up?" (12).

One other concern is that the surgeons would take credit for scientific progress on the one hand and regard these criticisms as obsolete and dogmatic but challenging.

\section{Letter to the Editor}

In July 2013, Canavero published a paper in which he explained the GEMINI project (1). Another paper on the topic was published in 2015 (2). Canavero and Ren published a paper together in 2016 (10).

The last sentence of the first article reads as follows: "This paper lays out the groundwork for the first successful human head transplant." Later, referring to Canavero's 2007 paper (1), in a letter to the editor of Surgical Neurology International (3), Čartolovni and Spagnolo, bioethicists at the Catholic University of Sacred Heart, Rome, Italy, outlined their concerns and some ethical considerations after reading Canavero and Ren's paper with "interest and some perplexity." The journal editor published the letter along with Canavero's commentary on the notes (3). Canavero's reply is of particular importance with regard to the ethical approach to head transplantation. It began with the following quotation from Immanuel Kant:
"Upon a slight conjecture, I have ventured on a dangerous journey, and I already behold the foothills of new lands. Those who have the courage to continue the search will set foot upon them...." Canavero was thus acknowledging and appreciating the greatness of this philosopher, but he was also trying to take advantage of it to rationalize his own attempts.

Drawing attention to the uncertainty regarding the technical feasibility of the GEMINI procedure even for neurologists, Čartolovni and Spagnolo noted that the main question was how to connect the axons in the spinal cord properly even when they are cut precisely. If, as Canavero argued, the procedure is technically feasible, to which extent it is possible and feasible to perform is in dispute.

In response to Čartolovni and Spagnolo's concern regarding the difficulty of spinal cord anastomosis, Canavero gave only two exceptional examples of spinal cord restoration. The first example was the case of a 24-year-old woman injured in a high-speed skiing accident. In that case, the cord scar was removed, and collagen was inserted into the gap. Magnetic resonance imaging revealed that new axons and nerves grew in the spinal cord. In the second example, a Polish medical team obtained a culture of fibroblasts by combining spinal cord cells with olfactory cells for the treatment of spinal cord injury in a male patient. This culture was implanted in the damaged spinal cord to form axon bridges in the spinal cord area without neural connection (2).

Canavero will not find support in the medical world if he continues defending the rationale for head transplantation on the basis of such examples (2).

From the perspective of scientific ethics, interventions whose results are not presented in the form of quantitative statistics cannot be performed in human beings. The GEMINI project that Canavero developed for spinal cord anastomosis must first prove to be reliable and valid methodologically on less severe injuries. Revolutionary innovations in science must be based on existing knowledge and evidence.

There is a distinction between experiment and trial: It is not possible to predict the outcomes of an intervention that has never been tried previously. Medical progress is necessary for the prosperity of society, and experimental surgery is a significant instrument for medical progress. However, medical progress cannot build upon the elimination of respect for individuals and their autonomy or on the violation of the principle of beneficence (8).

According to Čartolovni and Spagnolo, the first ethical issue regarding the GEMINI procedure is experimentation on animals (3). They referred to the experiments of Robert J. White and Vladimir Demikhov, whose results confirmed that these experiments were lethal in animals, whereas animal welfare should be the primary concern in experiments. Because the GEMINI procedure is supposed to prolong life, the outcomes achieved so far must play a significant role in decision making.

Canavero argued that millions of animals were killed every year for academic research to be published in prestigious journals. Yet, no solid achievement has yet ben obtained. 
Canavero subjectively contended that his research was an exception. This attitude complies with neither scientific ethics nor animal rights. Which animal is aware of the significance of research for which it is sacrificed? Is Canavero, who set out to blaze the trail in medicine, not aware that advances in academic research build upon findings in previous research? Why does he measure the significance of research from his subjective perspective?

Canavero said that head transplantation could not be performed in Italy because of the Catholic law. This argument creates the perception that illegal and unethical procedures are legitimate in smaller countries that do not have religion-based rules. The practice of in vitro fertilization is already a subject of dispute between countries. Proposing the use of questionable procedures may lead to more significant problems. Canavero's argument implies that any doctor should be able to conduct unethical interventions in any country.

Čartolovni and Spagnolo were also concerned that patients undergoing head transplantation would need to take a great amount of immunosuppressive drugs; even if spinal cord anastomosis is successful, these drugs may not prevent tissue rejection (3). With regard to the concern regarding transplant rejection, Canavero mentions that new drugs used in recent research reduced the frequency of unnecessary drug use and that immune rejection is no longer a contraindication in head transplantation because of these new drugs.

Underlining the fact that successful brain transplantation must entail transplanting the person's mind, cognition, and personality; Čartolovni and Spagnolo stated that cognition is part of the formation of human self and that there will be significant difficulties to overcome in maintaining cognition of the person after transplantation (3). Furthermore, body shape and body image have strong effects on human identity, and even memories of the former body are likely to cause perplexities during the formation of a new identity. In response to these concerns, Canavero stated that recipients would be psychologically prepared before the head transplantation procedure, and the patient would be familiarized with the new situation by virtual reality and hypnosis methods.

Finally, Čartolovni and Spagnolo also questioned to whom the gonads would belong, assuming that head transplantation is successful (3). Canavero also addressed this question; he believed that the parents of the brain-dead donor would be comforted by the recipient's ability to produce their own descendants; that is, he believed that life will come out of death. However, he did not consider the ethical problems that are likely to arise, such as transsexualism in people with a different sexual orientation or the desire to have the body of the opposite sex.

\section{Cartesian Dualism and Head Transplantation}

One of the reasons for the media coverage of the discussion of head transplantations is that the idea of merging someone else's head with a body of another person is very strange for people and may generate bizarre emotions. In society, it is generally understood that a body and a head are the two basic elements of a healthy person and are integrated with each other. The idea that this dualist structure can be corrected again when it breaks has aroused some ontological curiosity with regard to individual autonomy. In the history of thought, the dualist understanding of the soul-body connection emerged before that of the head-body connection.

The idea that human beings are created from a body and a soul is a belief that is generally accepted in most societies; it has existed at least since the emergence of monotheistic religions and possibly even since prehistoric periods. The idea of body and soul that shaped people's ontological thinking is a prerequisite for the answers to the questions asked about human existence. In medieval Europe, the concept of soul was at the center of Christian religious understanding. In fact, at that time, it was believed that the soul was able to connect with God and exist forever, in contrast to the transient and mortal physical body. On the one hand, medieval Christian scholasticism revolved around the absolute will of God, the idea that the mind of God dominated in all things, and the acceptance that the human soul and mind must be subservient to God. On the other hand, the distinction between the world of ideals and phenomena based on Plato's writings and the philosophy of ancient Greece has reinforced the understanding of the dualistic structure of the body. The discovery of a continent outside the known world toward the end of the Middle Ages, the tremendous developments in the field of astronomy, and many other discoveries showed that the things do not function in the ways described by the church. With the Renaissance, a rebellion against the concepts and methods of the Middle Ages began.

The Renaissance was a period in which the human mind came to the forefront of scientific study with the humanist approach. With the rise of rationalism in the $17^{\text {th }}$ century, medieval understandings became suspect, and Rene Descartes (15961650) developed a methodological philosophical system in which nearly everything could be doubted. The only thing he never doubted was the existence of doubt. According to Descartes, human beings could present themselves as individual entities from the moment they could say that "I think" and explore their relationship with other objects. This inference gave rise to the subject-object distinction that is the basis of the Cartesian philosophy. In this philosophy, a distinction is made between mind and body, and the brain is considered the master of the body. Descartes viewed the brain as the master of the body, believing that the mind renders human beings superior to other living things and that mind is located in the brain (i.e., in the head) (5). The idea that "brain is the master of body," suggested by Descartes four centuries ago, has been confirmed over the years through scientific progress, especially thanks to developments in neurology and neurosurgery. Not only our ability to think, reason, and recall but also all our cognitive identity, including experiences and past, are located in the brain (i.e., in the head).

The subject is the center of knowledge because it manifests itself through thinking action. In the spirit-body dualistic concept of the Middle Ages, the spirit evolved into the subject, and it is now defined and understood as being intertwined with concepts such as self and cognitive identity. The idea 
that the subject - the representation of a person who thinksis the real owner of the body, has increased the reputation of the body. On the basis of the subject-object division, Kant, who followed the Cartesian tradition, constructed the concept of individual autonomy that underlies the contemporary liberal understanding. According to Kant, the subject is not always a tool but is always a goal; the subject as a human being is always more valuable than the objects around him or her (4). This approach is the foundation of medical ethics and other occupational ethics in which people are the focus.

To make a distinction between object and subject in head transplantation, physicians need to answer three questions: whether it is the head or the body that is transplanted, which one is the object, and which one is an instrument for the object (i.e., the subject). These questions may be thought irrelevant to the entire procedure of head transplantation. However, we emphasize that they are of primary importance to understand the value attributed to donor and recipient in ethical analysis. "Transplantation" entails carrying one thing to another place or removing it and placing it into a new place. The process of head transplantation is planned as the combination of the recipient's head and the donor's body. In this framework the latter's cerebral death is certain and here is no possibility of healing again. In this scenario, the cognitive identity, which will be provided continuance if the procedure is successful, belongs to the head. The subject of the process is the head; the transferred body is an object that serves the subject.

Calling a body with a dead brain a "corpse" requires us to show respect deserved by the dead individual, not a living one. Undoubtedly, this process does not mean that less respect should be shown to a body used as a donor. Head transplantation must be a two-way process in which the recipient's body, which is separated from its own head, is to share a final resting place with the head of the donor and by this way, the respect will be shown to the donor. During the Turin Modulation Group Meeting in November 2017, the announcement of the head transplantation performed on two human cadavers is contradictive to human dignity even if they are corpse. The ultimate goal of the head transplantation is the survival and the movement of the head transplanted to a new body. The process of Ren and his surgical team that enables Canavero's work on cadavers is not compatible with either morality or science.

Canavero may prefer to name this process "head transplantation" in order to create a sensation in the public. Such slogans generally bring about populism, which is mostly venomous for science and subsequently helps fulfill personal interests. As a matter of fact, both Canavero and the media objectified Valery Spiridonov and the procedure known as head transplantation for the sake of personal and social interests. Science, by its very nature, must not objectify a subject.

Canavero attempted to turn science-an instrument developed for the prosperity of society -into a performance by using a subject: Mr. Spiridonov. In society, science is viewed as a goal, and Mr. Spiridonov is viewed as a person sacrificed for the sake of a predetermined goal. This procedure is normalized under the pretext of advances in science.

In television stories regarding head transplantation, the image of Valery Spiridonov in his wheelchair controlled by his commands reminds us of Stephen Hawking, the worldrenowned physicist and cosmologist. Hawking received a diagnosis of amyotrophic lateral sclerosis in 1963, when he was 21, and he passed away in March 2018. During his life, he was able to transfer his valuable views about the universe by means of specialized devices. Some people inevitably developed an optimistic association between Hawking and the concept of "head transplantation." What places Hawking at the center of this perception is that he took full advantage of science in his struggle with the disease, and science was an instrument that made life easier for him, a subject. However, studies in which the subject is a goal should not be confused with studies that instrumentalize the very presence of a subject. Science exists for the sake of human beings; the existence of human beings is not for the sake of science.

\section{Media, Society, and Science}

Canavero also stated the following in his reply to the editor: "The recent renewed effort toward achievement of the arguably most ambitious medical enterprise ever-reconnecting a head to a body - has sparked a global controversy of biblical proportion, reaching tones bordering on fanaticism-not to mention slander" (3).

Canavero had already mentioned in his reply to Čartolovni and Spagnolo's considerations that he was one of the reformers in science, a trailblazer who contributes to the advancement of science. After the reports in newspapers, Canavero described public opinion as follows: "...the world of medicine is roughly split into two camps: On one side, highly vocal critics, often from the academe, on the other, a growing-but mediasilent-army of enthusiastic supporters writing or calling to be part of this 'historic' first surgery." Canavero defines planned head transplantation surgery as a medical "moonshot" (3).

Scientists have always struggled against dogma before introducing an innovation, and belief systems have always impeded the advancement of science. The struggle against the church in Europe in the Middle Ages is one of the examples. In the beginning, people tended to object to innovations in parallel with their society's belief system, considering that a new initiative might have negative effects on their ethical values and compromise the status quo. However, over time, this tendency was weakened by the spread of positivism, which was supported by rationalism, and by the perception that technical advancements improved the prosperity of individuals and societies. This perception increased people's interest in science and induced a sort of peace between science and religious belief. This favorable climate served as a source of motivation for each attempt that was likely to improve social welfare, especially in the $20^{\text {th }}$ century. As a result of this, the perception of science in society has been so positive that people started to believe any scientific attempt serves to improve social welfare, and it is wrong to question science. Religious belief systems were almost replaced by 
science. However, fake scientists and modern charlatans started to act under the guise of science taking advantage of the positive perception of science in the society.

In conflicts between society and science, the media has always focused on the more powerful of the two. On the one hand, the media is influenced by perceptions of the society; on the other, it also shapes those perceptions while communicating the public opinion. The perspective of society may not always lead to the ethical path in science. The expectations about how science affects welfare and the subjectivity attributed to science can influence the choices that people make. The self-serving choices push the limits of morality. Unfortunately, democracy is insufficient or functionless in the specializationrequired branches such as science. The proper perspective of society can be possible only with knowledge about science. The more that people know about science, the more they tend to eliminate mediators between society and science.

From a historical perspective, the Nuremberg trials constitute an example of the fact that scientific research based on motivation from the political power (i.e., the actions taken according to the perception and support of society) does not always remain within ethical limits.

Who is going to determine the limitations of tolerance toward scientists, considering the positive perception that science is "great" and can solve any problem in the society? In each field of science, investigators conduct research according to its paradigms with the power of accumulated knowledge. For instance, the research of Dmitri Mendeleev, Marie Curie, and Ernest Rutherford are milestones in chemistry. These scientists are as esteemed as the philosophers who transformed the movements of thought and thus changed the world. In the same vein, ethics, as a field of science, has to be used to determine the norms regarding the relationship between society and science. Ethics should enlighten the points that are not visible to the public in scientific research and determine the limits of tolerance according to the ethical values of a given society. As specialists in a field of science, ethicists should do their best to make scientific paradigms public in order to motivate people to show as much interest in ethics as they show to other scientific disciplines. Ethics is a field of science in which science and society are observed and protected, and it helps prevent misconduct. By doing so, ethics sheds light on scientific progress for the prosperity of society. Ethics, as a field of science, can never be used by ideologues.

People's interest in, curiosity about, and support of science provide a source of motivation for scientists. With this motivation, scientists can focus more on topics that have been dreamed by the society. What underlies the positive perception about Canavero's head transplantation plans is the eternal dream that humanity has aspired to achieve: immortality. Throughout the history, the greatest goal of all sorcerers, charlatans, and alchemists has been to achieve immortality. Human beings are afraid of uncertainties hidden by death. Adherents to belief systems have always ostracized and penalized people seeking immortality, considering that they revolt against God and God's commands. Initially, the idea of immortality was perceived as a stance against the religious and ethical status quo; however, over time, its effects have gone beyond belief systems with the spread of the argument that accurate knowledge also exists outside of belief systems. People with religion-based ethical values seemed not to respect charlatans' or alchemists' search for immortality.

Nevertheless, there had always been a small but distractive curiosity in their mind, the question "Is it possible?" This curiosity became stronger and more legitimate when ethical aspects of belief systems lost influence with scientific advancements. Populists who desired to turn a dream into reality started to take action as the idea of immortality became more tenable and religious obstacles were removed. Throughout history, charlatans have been ostracized, always by the scientific community but only periodically by adherents to belief systems. The driving forces of science are the rule of falsifiability (inherent nature of science) and ethics (as an inclusive framework). Belief systems used to be in charge of ethical control in scientific research. Today, in deontological approaches-in other words, ethics as a field of science in its own right-the subject is the focus, and normative codes are developed specifically for each scientific field.

For now, the ultimate goal of medicine is to heal people and to extend life. Extending life is the most fundamental goal of medicine with regard to human prosperity. Straight forward logic suggests that medicine achieves its ultimate goal when life is extended eternally (i.e., when immortality is achieved). However, head transplantation, which is publicized as a way of achieving immortality, is not the ultimate goal that medicine aspires to achieve. It is a medical goal in terms of neither ethics nor science. It is not ethical to allow some people to die so that others achieve immortality.

\section{Existence and Head Transplantation}

In the subject-object distinction of Cartesian philosophy, as described earlier, subjects present themselves as individual entities only from the moment when they can say that "I think" and explore their relationships with other objects (5). In other words, thinking is an absolute condition for the subject to exist.

Patients planning to undergo head transplantation (or more correctly, transplantation of a body without the head) in order to eternalize their existence may be faced with four possible consequences, depending on the success of surgery. First, the head above a body that is to be transplanted will die, in biological terms. Therefore, if the donor loses his or her biological existence, the concept of "thinking" is irrelevant to the donor.

Second, brain damage is likely to occur if the slightest problem arises in blood circulation between body and head. In such a case, it is not possible to predict the prognosis, whether the patient is going to survive or not, or whether the patient will be able to think or not. If we assume optimistically that problems such as transplant rejection and complications of spinal cord anastomosis are overcome, the head in such a case will nonetheless be at a disadvantage in comparison to its previous situation. 
Third, spinal cord anastomosis may not be successful, even if blood circulation between body and head is ensured. A patient who undergoes head transplantation may have brain functions (i.e., be able to think) but may be unable to perform its body functions. This also means that the head, as a subject, will be at a disadvantage in comparison to its previous existence.

Fourth, to be able to conclude that head transplantation is successful, the existence of the head, together with the body to which it is attached, as a subject, must be in a better situation than before surgery. Under today's medical conditions, to consider a head transplantation successful, blood circulation between head and body must be ensured, spinal cord anastomosis must be achieved, transplant rejection must be prevented, and the patient must undergo physical rehabilitation for years even to restore the smallest functional ability. Even if all these medical obstacles are overcome, it is not possible to know whether cognitive identity and thinking ability of the new being will be better than those of the previous being.

A person may set out to eternalize his or her existence. However, today's medicine, as an instrument, cannot help the person achieve this goal. A person cannot be immortal without existing.

\section{REFERENCES}

1. Canavero S: HEAVEN: The head anastomosis venture project outline for the first human head transplantation with spinal linkage (GEMINI). Surg Neurol Int 4 Suppl 1: S335-S342, 2013

2. Canavero S: The "Gemini" spinal cord fusion protocol: Reloaded. Surg Neurol Int 6:18, 2015

3. Čartolovni A, Spagnolo AG: Ethical considerations regarding head transplantation. Surg Neurol Int 6:103, 2015
4. Cevizci A: Aydınlanma Felsefesi. Bursa: Ezgi Kitabevi Yayınları, 2002:258

5. Descartes R: Metod Üzerine Konuşma. Trans: Şahirsel K. İstanbul: Sosyal Yayınlari, 1984

6. Head transplant carried out on monkey, claims maverick surgeon. https://www.newscientist.com/article/2073923head-transplant-carried-out-on-monkey-claims-mavericksurgeon/ Date of Access: 10 May 2017

7. Human head transplant edges closer to reality: Chinese surgeon teams up with Italian doctor to perform controversial procedure in 2017 http://www.dailymail.co.uk/sciencetech/ article-3227954/Human-head-transplant-edges-closerreality-Chinese-surgeon-teams-Italian-doctor-performprocedure-2017.html Date of Access: 10 May 2017

8. Kadioglu F, Dalay C, Uzel İ: Yüz Aktarımında Etik Sorunlar. İstanbul: 1. Uluslararası Tıp Etiğive Tıp Hukuku Kongresi Bildiri Kitabı, 2007: 822

9. Kafa nakli için tarih verdi. http://www.ntv.com.tr/saglik/ kafa-nakli-icin-tarih-verdi,2m68N_BUu0m6O6Jn9Q3tGg?_ ref=infinite Date of Access: 10 May 2017

10. Ren X, Canavero S: Human head transplantation. Where do we stand and a call to arms. Surg Neurol Int 7:11, 2016

11. The surgeon who wants to perform a head transplant by 2017. http://www.bbc.co.uk/newsbeat/article/37420905/thesurgeon-who-wants-to-perform-a-head-transplant-by-2017 Date of Access: 10 May 2017

12. World's first human head transplant a success, controversial scientist claims. http://www.telegraph.co.uk/ science/2017/11/17/worlds-first-human-head-transplantsuccessfully-carried/?WT.mc_id=tmgoff_fb_tmg\# Date of Access: 19 November 2017 